\title{
PARADOXICAL TENSION: BALANCING CONTEXTUAL AMBIDEXTERITY
}

\author{
M. Vettorello ${ }^{\otimes}$, B. Eisenbart and C. Ranscombe \\ Swinburne University of Technology, Australia \\ $\triangle$ mvettorello@swin.edu.au
}

\begin{abstract}
The concepts of high-velocity, complexity and interdependency are nowadays vividly discussed in design-led innovation management. Design organisations seek to manage innovation in a more dynamic way to ensure competitive advantage and long-term competitiveness. Contextual ambidexterity is advised to be a dynamic capability that can facilitate firms to effectively manage incremental and radical innovation alike. This paper proposes an approach that focuses on the individual and the underlying thinking which bases its foundations on ambidextrous leadership, abductive reasoning and strategic fit.
\end{abstract}

Keywords: innovation management, design theory, design strategy, ambidexterity, abductive reasoning

\section{Introduction}

Managing design innovation is becoming ever challenging for organisation which has to evolve the way they do it. Due to high complexity and interdependency of elements, only a handful of firms have been able to fully grasp what it is required to spark innovation effectively (Christensen, 2003). On this note, Nicholas et al. (2015) state that finding a balance between incremental innovation trajectory (exploitation of available ideas in a short-term timeframe) and radical one (exploration of novel ideas with a long-term timeframe) is essential for organisations that want to stay competitive in their market. In other words, design organisations need to balance exploration and exploitation in design innovation management in order to ensure long-term survival (Raisch and Birkinshaw, 2008). The idea is to not miss the 'next wave', rather that significant change in the market provides huge opportunity but also pressure to follow. A well-known example is the change from analogue to digital photography, famously missed by Kodak. Moore (2015) compiled a whole list of organisations that missed the 'next wave' in their respective markets. This shows the importance of mastering a dynamic capability to balance both trajectories at the same time to stay competitive and create new value (Duncan, 1976). This capability of an organisation to engage in both radical and incremental innovation in parallel and in a well-balanced manner is referred to as ambidexterity (Turner et al., 2013; Nicholas et al. (2015); Hamel, 2002; O'Reilly and Tushman, 2008). Salampasis et al. (2015, p. 43) argue that it is 'important to lead an ambidextrous thinking and strategy towards sensing the need of change and at the same time being able to develop the right actions in order to reply to all these existing opportunities and threats.' As an early evidence of this, Grant (1996) and Kogut and Zander (1992) suggest that the ability to wisely reconfigure competencies and resources is extremely critical in high velocity markets. For this reason, companies should strongly 
focus on designing ambidextrous eco-systems and scout for ambidextrous design leaders. Such leaders have particular skills: the capability to switch behaviour between innovation context as per exploitation and exploration, and ingeniously manage the internal resources of the organisation to effectively foster both (Kraner, 2018). Scholars suggest that by achieving ambidexterity design organisations should benefit by increasing in revenue, profit and productivity growth (Lin et al., 2013) as well as generate a significant competitive advantage (O'Reilly and Tushman, 2008). Despite this call for ambidexterity from established research, many organisations struggle to truly implement it (Christensen, 2003). This is often referred to as 'balance problem' and yields a critical gap in a company's position to manage design innovation effectively (Nicholas et al., 2015; Hamel, 2002). Difficulty in achieving a balance is seen in a strong bias in favour of exploitation because it conveys greater certainty of short-term success (O'Reilly and Tushman, 2013). Whilst, radical innovation is seen as highly challenging due to greater uncertainty and needing more consideration, it can change current paradigm and push the organisation on top of its market as well as support long-term strategy, but also has intrinsic higher risks. Regardless of whether the organisation is seeking for radical or incremental innovation, it still must make the 'right' decisions as to which particular innovation idea to engage in to leverage positive return and thus remain competitive in the market.

Building upon Nicholas et al. (2015); O'Reilly and Tushman (2013) and Christensen (2003), this paper objective is to explore the current state of organisational ambidexterity in innovation and propose an approach to reduce the discovered 'Balance Problem' gap and manage contextual ambidexterity in innovation with the support of ambidextrous design leaders. In particular it focuses on the individual level (based on microfoundation theory) to explore design leadership qualities to suggest an approach to reduce the 'Balance Problem'. And in turn improve the way innovation is managed. The paper is structured as follows. Section 2 presents a systemic review of extent literature that focuses on ambidexterity. Then, Section 3 follows with an exploration of the ambidextrous design leader and inherent thinking, forming the basis of our proposal to manage contextual ambidexterity in Section 4. Conclusions and possible future research avenues are presented in Section 5.

\section{The paradox: Managing exploration and exploitation}

In the early literature on ambidexterity, the context of reference is typically closely related to strategic management at the organisational level, considering the whole organisation as a more or less homogenous entity (Duncan, 1976). Research has since focused on the role of leadership and thus, ultimately, of individual leaders in formulating and orchestrating innovation through their organisations. This gave rise to an increasing literature on the individual level in managing design innovation where different researchers (Raisch and Birkinshaw, 2008; Andriopoulos and Lewis, 2009; Nosella et al., 2012) suggest ambidexterity as an individual capability needed to embrace the tension and through the right leadership. We conducted an exploratory systemic review to outline the current state of ambidexterity. In the following, we present a summary of the key points evinced in the literature, which is filtered by Dresch et al.'s (2015) criteria. Sources are drawn from areas like design, entrepreneurship, business, innovation management and leadership, based on keywords such as: ambidexterity, organisational ambidexterity, dynamic ambidexterity, simultaneous innovation, ambidextrous innovation. Empirical studies show that (i) firm performance is positively affected by ambidexterity in conditions of market and technological uncertainty (see Junni et al., 2013; O'Reilly and Tushman, 2013). Organisations that embrace and have mastered ambidexterity are more successful because they are more reactive to market change financially outperforming single-focused organisations, and have capability-growth and innovativeness (see also Caspin-Wagner et al., 2012; Tushman et al., 2010; Auh and Menguc, 2005; He and Wong, 2004; Tushman and O'Reilly, 1996; Raisch and Birkinshaw, 2008; Simsek, 2009); (ii) there is evidence that show that both types of innovation are beneficial to each other and they can respectively cross-pollinate with knowledge and expertise (Katila and Ahuja, 2002; Knott, 2002); and (iii) suggest three types of how to conduct ambidexterity, namely sequential, structural and contextual ambidexterity of which each requires a different structure, mindset and approach in order to achieve it (Birkinshaw and Gibson, 2004a; O'Reilly and Tushman, 2013; see Table 1). A strong focus is upon the structure and how this plays an important role in the contextual ambidexterity, Birkinshaw and Gibson (2004a, p. 201) say that a team leader should build 'a set of processes or systems that enable and encourage individuals to make their own 
judgments about how to divide their time between conflicting demands for alignment and adaptability'. So, the he/she is highly influencing the mindset and approach to innovation of his/her team. It is important to highlight why contextual ambidexterity is so beneficial: both trajectories are pursued by the people from the same department which means a better information management and cross fertilisation of innovations, and there is a culture of innovation which invites for exploration and accepts failure (O'Reilly and Tushman, 2013). This organisational culture is illustrated by Adler et al. (1999) looking at the well-known Toyota model of Kaizen. In Kaizen, employees perform exploitation activities and are asked to change their job within an organisation regularly to learn new skills (exploration activities). Firstly, the emphasis is put on the person, their personal curiosity and interest in exploration (Individual level). Secondly, by helping the individual level this will eventually influence the other levels too because it scales to team level like people forming the unit have a common understanding and alignment of contextual ambidexterity (Team level) and ultimately to organisational level where organisational systems promote flexibility, discipline and trust (Organisational level) (O’Reilly and Tushman, 2013).

Table 1. Types of ambidexterity

\begin{tabular}{|c|c|c|c|}
\hline & $\begin{array}{c}\text { Sequential } \\
\text { Ambidexterity }\end{array}$ & $\begin{array}{c}\text { Structural } \\
\text { Ambidexterity }\end{array}$ & $\begin{array}{r}\text { Contextual } \\
\text { Ambidexterity }\end{array}$ \\
\hline Characteristic & $\begin{array}{l}\text { Exploitation and Exploration } \\
\text { are sequentially conducted } \\
\text { based on market shift }\end{array}$ & $\begin{array}{l}\text { Exploitation and } \\
\text { Exploration are } \\
\text { conducted in separate } \\
\text { units or teams }\end{array}$ & $\begin{array}{l}\text { Exploitation and Exploration } \\
\text { are within one single unit and } \\
\text { contextually divided by the } \\
\text { employee that set aside times } \\
\text { for both. }\end{array}$ \\
\hline Level & Organisational & Organisational & Organisational + Individual \\
\hline $\begin{array}{l}\text { Dependant/ } \\
\text { Influence }\end{array}$ & Market shift & Departmental structure & $\begin{array}{r}\text { Explorative and venture } \\
\text { mindset }\end{array}$ \\
\hline Time of action & $\begin{array}{l}\text { Each phase is independently } \\
\text { conducted }\end{array}$ & $\begin{array}{c}\text { Conducted } \\
\text { simultaneously but in a } \\
\text { separated manner }\end{array}$ & $\begin{array}{r}\text { Both are run simultaneously } \\
\text { and within the same } \\
\text { department }\end{array}$ \\
\hline $\begin{array}{l}\text { Organisation } \\
\text { role in the } \\
\text { market }\end{array}$ & Followers & BAU & Leader \\
\hline Manager role & $\begin{array}{l}\text { Understand the market shift } \\
\text { and adapt accordingly }\end{array}$ & $\begin{array}{l}\text { Define the structure and } \\
\text { trade-off between } \\
\text { exploitation and } \\
\text { exploration }\end{array}$ & $\begin{array}{r}\text { Act as a creator and leader of } \\
\text { ambidextrous culture and } \\
\text { resources }\end{array}$ \\
\hline Culture & $\begin{array}{l}\text { There is a culture of taking } \\
\text { action when needed, } \\
\text { following the market shift }\end{array}$ & $\begin{array}{l}\text { There is a culture of } \\
\text { following internal } \\
\text { methodologies and way } \\
\text { of doing }\end{array}$ & $\begin{array}{l}\text { There is a culture of } \\
\text { flexibility and discovery }\end{array}$ \\
\hline $\begin{array}{l}\text { Employee's } \\
\text { skills }\end{array}$ & Specialist & Specialist & Generalist \\
\hline
\end{tabular}

Instead, sequential ambidexterity is characterised by changing process and structures following shifts in market condition (see also Lovas and Ghoshal, 2000). This is predicated on the assumption that the innovation pace allows enough time to the organisation to change trajectory, usually it is described as sequential phase of exploration and rigid exploitation (O'Reilly and Tushman, 2008). Structural ambidexterity is related to the organisation having two departments for each type of innovation, one that focuses on business-as-usual (hereon BAU) (incremental innovation) and the other one focuses on research and development of novel ideas (radical innovation). In addition, the two departments also minimise communication in order to mitigate possible distractions, influences and blockages, as opposed to cross-pollinate ideas, but they share resources to reduce internal cost. In regards to this, Rothaermel and Deeds (2004) refer to incremental innovation as the way to gain revenue that can foster the exploration of innovative ideas. This is similarly proposed by Paap and Katz (2004) who 
argue that companies that do not have a solid and strong innovation culture often step into the organisation dualism barrier (see also Assink, 2006) where incremental and radical innovation are sought but internally there is a conflict that slows down the design process. Often, the exploration of new alternatives involves creators and inventors who possess a high level of creativity, and that can specialise in generating novel ideas without feeling the pressure that the market generates (external pressure) and the influence from the BAU department (internal pressure) (Assink, 2006; O'Connor, 2008; O'Reilly and Tushman, 2011). Hence, there is an underlying tension between the two trajectories of innovation. The explorative or radical innovation must account for flexibility, alternative reasoning, proactiveness and autonomy, and experimentation, whereas the exploitation or incremental journey requires efficiency, control, rigours and of course incremental improvements (Tushman and O'Reilly, 1996; Benner and Tushman, 2003; Raisch et al., 2009; Turner et al., 2013).

In support to the above, Devinney (2013) highlight the importance of the individual, and states that there is a gap to be bridged on how management theories have been researched and conceptualised. Mainly because the individual is taken out from the equation when focusing on, for example, organisational level and departments scope. This because, even thought contextual ambidexterity is said to be beneficial to manage innovation, it is still unclear what should be the characteristic of and who should lead the innovation journey, and how to operationalise and close the gap between the organisation vision and the innovation department. Here, Microfoundational theory is suggested to create value because it focuses on the individual at each organisational level and looks at the organisation from a system and interconnectedness perspective (Devinney, 2013; Eisenhardt et al., 2010). Thus, microfoundational theory create value by shaping the underlying thinking which in turn supports contextual ambidexterity. Devinney (2013) further defines four levels of microfoundation theories Individual-level theory (I-theory), Organisational-level theory (O-theory), Strategic-level theory (S-theory) and Aggregation Theory (A-theory) (see Figure 1).

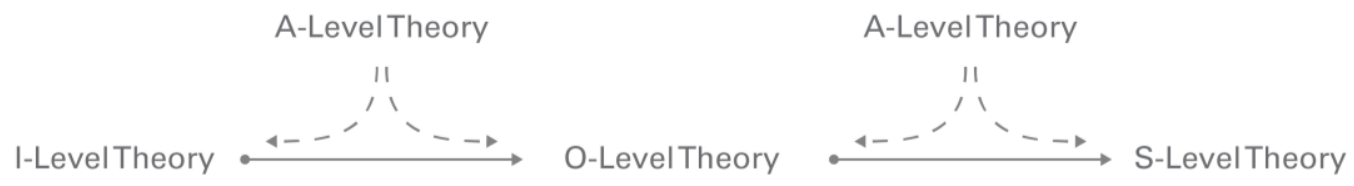

Figure 1. Microfoundations level-theories (adapted from Devinney, 2013)

Within microfoundations, the underlying actions at I-Level and O-Level that inform strategy and build dynamic capabilities, which is likely to result in S-Level performance (i.e. Ambidexterity efficiency/exploitation and flexibility/exploration) (Eisenhardt et al., 2010; Brown and Eisenhardt, 1997; Tushman and O'Reilly, 1996; Uzzi, 1997). On this note, Barney and Felin (2013) state that analysis of these levels is often highly structured and siloed. For example, I-theory is likely to focus on the nature of individual characteristic such as risk disposition, biases in decision making and the influence of mental model, while S-theory may place emphasis on the utility maximisation and firm-growth decision making, and discounts for the influence of individual bias. However, the organisation is not making these decisions, rather it is individuals that make S-theory decisions. As such there is often a misalignment between the three levels. Microfoundation theory bridges this structural analysis of organisational management (see Barney and Felin, 2013; Devinney, 2013) and observes it from an aggregation lens. A-theory is therefore the internal level that explores the connection of each higher-level with the lower-level concepts in order to reach a shared language. However, it is a many-to-many relationship, so it is impossible to have linear communication. It is an aggregation and reshape of knowledge that moves to a higher-level (Shapiro, 2000). For example, several I's shape an O-level and many O's make an S-level. Here, O-theories are to the key link between S-level and I-level but how this work has not been formalised and is generally understudied (Devinney, 2013). What is understood is that individuals are at the base of each level, and individual influencing traits should be accounted for when exploring strategies and organisational dynamic capabilities. Following this line of reasoning, we focus on the individual to increase organisational ambidexterity. In the context of design innovation management, it is inferable that a crucial aspect is 
understanding at the individual level which leadership skills are needed to operationalise contextual ambidexterity within design companies.

\section{The ambidextrous design leader: Leading the tension}

Concluding from the above discussion, contextual ambidexterity seems to have the biggest yielding power; however, it is not clear how to operationalise in design innovation management and intervene at the O-level (Devinney, 2013). The specific skills and actions that facilitate ambidexterity are still unclear. In addition to this, Turner et al. (2013) suggest that ambidexterity is often discussed on what it brings as a result and not what managers do to foster and generate an ambidextrous culture of innovation. For this we looked into leadership literature to distil what is described as effective leader (see Table 2). Furthermore, focusing on I-Theory, elements such as flexibility, alignment and control are intrinsic parts of contextual ambidexterity (Khazanchi et al., 2007; Eisenhardt et al., 2010). Trust, common identity and a feeling of freedom are contributing positively to this as individuals know that initiative can be brought forward, there is a collaboration attitude, expansion of skill and the ability to perform multitasking (Birkinshaw and Gibson, 2004a). The result is a common identity which mainly creates a sense of belonging, enhance trust, improve accuracy and support long-term collaboration. This implies having an understanding of thinking and doing toward a shared vision (Birkinshaw and Gibson, 2004b).

Table 2. Qualities of a leader (summarised from Kraner, 2018; Mumford et al., 2000; Arruda, 2016; Bennis, 1989 and Conger and Kanungo, 1987)

\begin{tabular}{|l|r|}
\hline Qualities of a leader \\
\hline Creative & Volition attitude \\
\hline Innovate for the entire organisation & Intrapreneurship \\
\hline Development of ideas & Influencing attitude \\
\hline Long-term thinking & Openness to change \\
\hline Challenge the status quo & Transformational leadership \\
\hline Create vision and meaning & High risk acceptance \\
\hline Do the right things & Abductive reasoning
\end{tabular}

From here we follow the concept of ambidextrous leader described by Kraner (2018, p. 37) and try to empirically link his/her role at O-level to contextual organisational ambidexterity described in Table 1 by splitting elements of contextual ambiguity between explorative and exploitative activities (visualised in Figure 2).

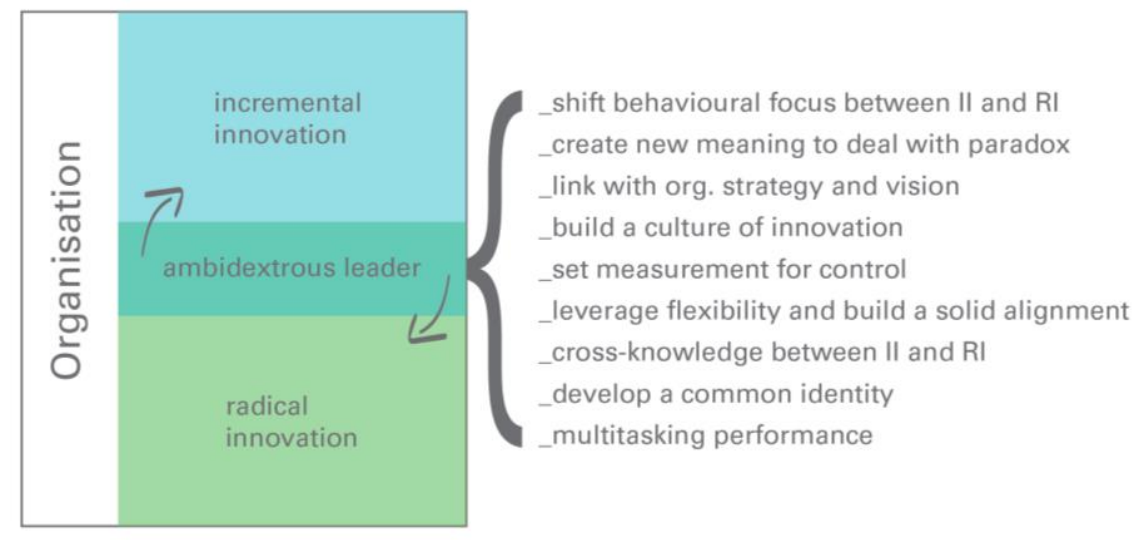

Figure 2. Position and characteristics of an ambidextrous leader

Based on this, an ambidextrous design leader should be able to help at O-level to select radical ideas from the explorative activities and help them transitioning to the exploitation department of the organisation in order to fit the organisational strategy. As a result, the radical innovation becomes the BAU (Moore, 2015). Moore (2015) explains the four quadrants (see Figure 3): incubation zone - 
lookout for radical idea to catch the 'next wave'; transitional zone - a radical idea is selected and moved to further development before it becomes the main organisation's market, here risks, investments and efforts are at most; performance zone - the BAU of the organisation and the refinement of current products, and productivity zone - everything else that relates with running the organisation.

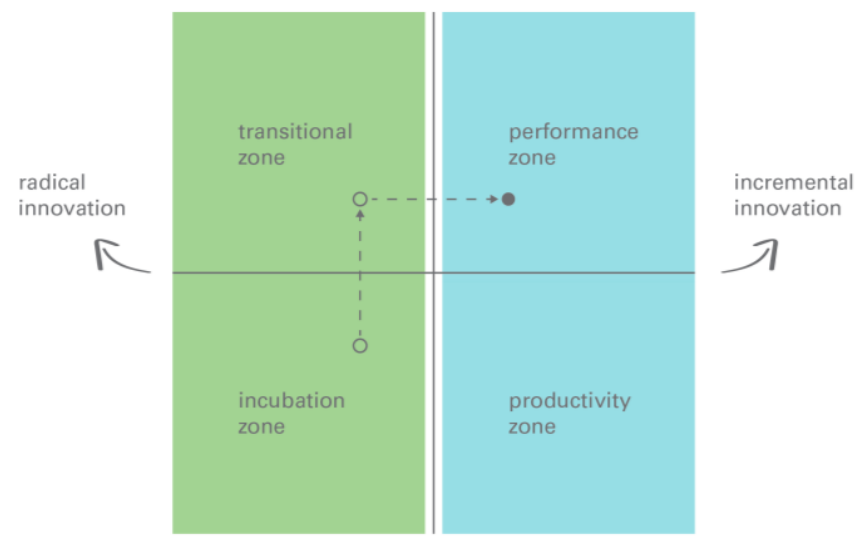

Figure 3. Four quadrants of ambidexterity (adapted from Moore, 2015)

In terms of managing the fours zone, return on investment in either the incubation zone and transitional zone are many years down the new product development journey. For this reason, radically innovative ideas are still in their embryonic stage - in the presence of high level of unknows, novelty and uncertainty - and cannot be immediately moved to the performance zone which is the revenue engine of the company. In this zone an iterative process to refine current marketable products is performed. The performance zone therefore is structural, it does not account for ambiguity and high uncertainty. The productivity zone is the one that make sure that the performance zone run efficiently and smoothly, hence it is part of the incremental type of innovation and the two go together in order to make sure that resource and capital are available for BAU. Even though this distinction helps understand the different stages, Moore says that the two activities - exploration and exploitation should remain separate. It is also not clear how the selection in the incubation zone should be conducted. We try to reduce the gap by focusing on the qualities regarding ambidextrous design leader listed in Table 1 - i.e. related to creating a vision, probe-and-learn, long-term thinking and new way of reasoning, and current research that focuses on divergently way of reasoning (see Dong et al., 2015, 2016; Dorst, 2011; De Bono, 2009). Figure 4 visualises the gaps.

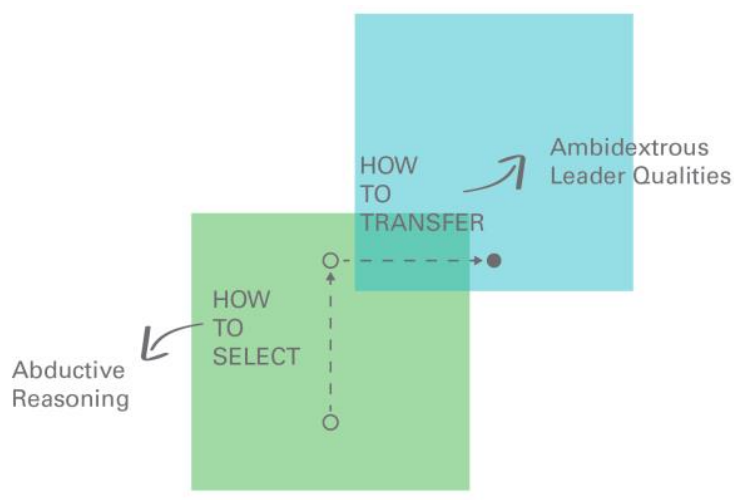

Figure 4. Contextual ambidexterity and gap

\section{A proposal to manage contextual ambidexterity}

Proceeding from the outlined qualities, Vettorello et al. (2019) present a summary of the literature highlighting that the generation of abductive hypotheses is supporting the decision-making process as to envision future trajectories leading to viable innovation opportunities. This very reasoning allows decision makers to conceive follow-up opportunities of the given options which exposes the person to stretch his/her 
imagination beyond what is proposed and direct their thinking to future opportunities. However, Smith and Lewis (2011) outline that there is a significant difficulty for organisations and leaders to hold paradoxical boundary conditions. Senior design leaders may handle and solve this paradox as underlined in Cao et al. (2009) and O'Reilly and Tushman (2011). Hence, we propose an approach that sits at the intersection of organisation management - ambidexterity and innovation management - and abductive reasoning whose aim is to support innovation management in design organisation Leveraging on solid research O'Reilly and Tushman (2011), Table 3 links strategic elements with organisational, tactical and operational level that highly benefit ambidexterity which sum our argumentation.

Table 3. Strategic elements to foster and maintain ambidexterity in organisation (adapted from O'Reilly and Tushman, 2011) with our strategy categorization at different levels

\begin{tabular}{|c|c|c|}
\hline $\begin{array}{l}\text { Level of } \\
\text { intervention }\end{array}$ & Element of Ambidexterity & $\begin{array}{l}\text { Our categorization of } \\
\text { organisational strategy }\end{array}$ \\
\hline Organizational & $\begin{array}{l}\text { A compelling strategic intent that intellectually justifies the } \\
\text { importance of both exploration and exploitation }\end{array}$ & Strategy fit \\
\hline $\begin{array}{l}\text { Organizational } \\
\text { and Tactical }\end{array}$ & $\begin{array}{l}\text { An articulation of a common vision and values that provide for } \\
\text { a common identity across the exploitative and exploratory units }\end{array}$ & Strategy differentiation \\
\hline Tactical & $\begin{array}{l}\text { A senior team that explicitly owns the unit's strategy of } \\
\text { exploration and exploitation; there is a common fate reward } \\
\text { system; and the strategy is communicated relentlessly }\end{array}$ & Strategy execution \\
\hline $\begin{array}{l}\text { Tactical and } \\
\text { Operational }\end{array}$ & $\begin{array}{l}\text { The ability of the senior leadership to tolerate and resolve the } \\
\text { tensions arising from separate alignments }\end{array}$ & Strategy communication \\
\hline Operational & $\begin{array}{c}\text { Separate but aligned organizational architectures (business } \\
\text { models, structure, incentives, metrics, and cultures) for the } \\
\text { exploratory and exploitative units and targeted integration at } \\
\text { both senior and tactical levels to properly leverage } \\
\text { organizational assets. }\end{array}$ & Strategy integration \\
\hline
\end{tabular}

Based on what has been discussed so far, we developed the following approach (see Figure 5) suggesting that organisation should seek for ambidextrous leaders that have the capabilities to be the linkage between exploration and exploitation. For example, Dyson has been able to share a vision (organisational level) and design innovative solutions by envisioning radical ideas as a continuous incremental journey (tactical and operational level) (The Leadership Network, 2016). Through discovery and experimentation Dyson has worked backward from the envisioned idea to develop small incremental steps to reach radical product and disrupting the market.

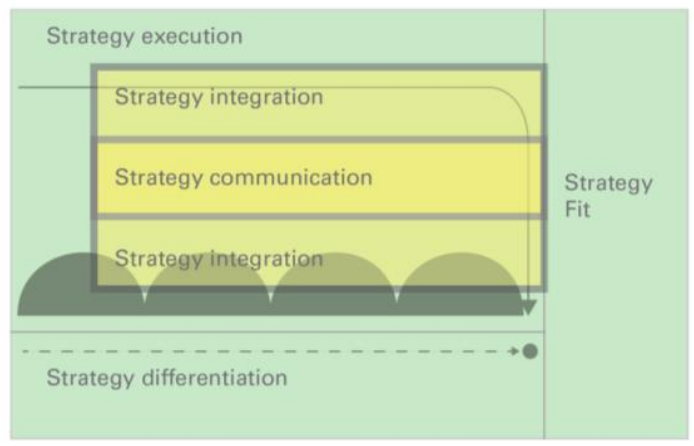

Figure 5. Fitting ambidexterity with organisational strategy

The proposed approach starts by outlining the 'Strategy Fit' that entails the envisioned future scenario generated by abductive reasoning and value creation. This also gives the rationale as to fund exploration of uncertain territories and dedicate resources for it, instead of pushing certain terrain and aim for shortterm targets. At the organisational level this answers questions such as 'what the current market looks like in 5, 10, 15 years'; 'what are customers' needs in the future'; 'what new technology could improve our product or generate new markets'. As per 'Strategy Differentiation', once a solid hypothesis is 
envisioned by using abductive reasoning, the organisation can work backward to define the explorative exercises in order to discover radical ideas that are able to reach a change of meaning (see Figure 6).

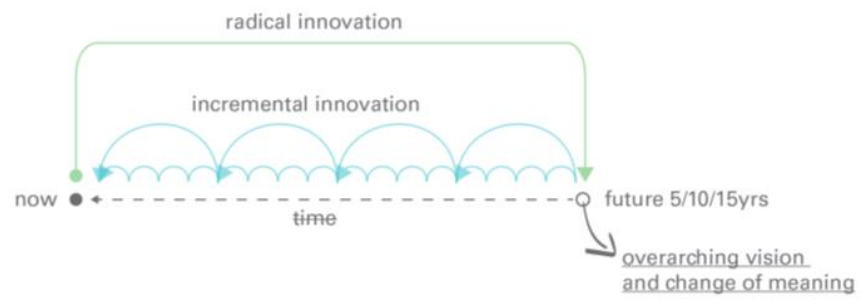

Figure 6. Contextual innovation approach

Here is the ability of the ambidextrous design leader to shift context (explorative and exploitative) and carefully observe the likelihood of knowledge and technical cross-pollination. The design leader has to enhance a culture of trust, adaptability and freedom as well as control which allow for individual exploration and maintain a level of accountability. This is also infused from the strategy fit at organisational level. Doing so provides the common understanding and promotion of trust, cooperation, and a long-term perspective highlighted in O'Reilly and Tushman (2011). Our presented model proposes that the exploitative and explorative departments should be aligned under one overarching vision and the design leader can act on dynamic capabilities and leverage organisational assets to support them (Strategy Integration). Furthermore, when there is not a clear alignment the design leader must have the ability to tolerate and resolve this tension (Strategy Communication).

\section{Conclusion}

By reviewing the literature on design innovation and organisational ambidexterity we observed what has been defined as to the "Balance Problem" paradox (Nicholas et al., 2015). We reviewed different types of ambidexterity outlined in extant literature - sequential, structural and contextual. From the review we find contextual ambidexterity and its intrinsic attention to the individual is fundamental for managing positively the two trajectories of innovation. Next, we reviewed literature that deals with leadership skills. Hence, we make the latter along with contextual ambidexterity and microfoundation the foundation of the suggested framework in order to manage exploration and exploitation more effectively and efficiently in design companies. From the review we propose an innovative approach to manage contextual ambidexterity in design companies. We argue that managing contextual ambidexterity requires a radical vision to be developed at S-level. Thus, by incrementally stepping backwords from this vision, the organisation can define resources, competences, technologies and processes needed in order to reach the envisioned new meaning while developing radical innovation. The ambidextrous design leader is presented to be the effective link between the operational and tactical level of the organisation and the organisational level. Thus, we conclude that the ambidextrous leader should be able to integrate product development while informing strategy, develop a sense of trust, flexibility, accuracy, respect and belonginess to enhance a culture of innovation. Implications for embracing this approach are likely to be seen for example in the context of innovation management specifically how this will influence the management and impact of innovation (i.e. the introduction of new reasoning such as abductive reasoning) or HR management - for instance, how characteristics of the ambidextrous leader will be endorsed and enhanced by the organisation to design leader. Future research will need to test the proposed contextual ambidextrous approach. Also define metrics to justify this approach which will ultimately inform the applicability and iteration of it in the context of design innovation management and how this could be well-integrated with the organisational strategy and BAU trajectory to increase flexibility and adaptability in a constant and high-pace market.

\section{References}

Adler, P.S., Goldoftas, B. and Levine, D.I. (1999), "Flexibility versus efficiency? A case study of model changeovers in the Toyota production system", Organization science, Vol. 10 No. 1, pp. 43-68.

Andriopoulos, C. and Lewis, M.W. (2009), "Exploitation-exploration tensions and organisational ambidexterity: Managing paradoxes of innovation”, Organisation Science, Vol. 22 No. 4, pp. 696-717. 
Arruda, W. (2016), 9 Differences Between Being A Leader and A Manager, Forbes, available at https://www.forbes.com/sites/williamarruda/2016/11/15/9-differences-between-being-a-leader-and-amanager/\#2f515aa84609

Assink, M. (2006), "Inhibitors of disruptive innovation capability: A conceptual model", European Journal of Innovation Management, Vol. 9, pp. 215-233. https://doi.org/10.1108/14601060610663587

Auh, S. and Menguc, B. (2005), "Balancing exploration and exploitation: The moderating role of competitive intensity", Journal of business research, Vol. 58 No. 12, pp. 1652-1661.

Barney, J. and Felin, T. (2013), "What are microfoundations?", Academy of Management Perspectives, Vol. 27 No. 2.

Benner, M.J. and Tushman, M.L. (2003), "Exploitation, exploration, and process management: the productivity dilemma revisited", Academy of Management Review, Vol. 28, pp. 238-256.

Bennis, W. (1989), Why Leaders can't Lead, Jossey-Bass, San Francisco.

Birkinshaw, J. and Gibson, C. (2004a), "Building ambidexterity into an organization", MIT Sloan Management Review, Vol. 45 No. 4, pp. 47-55.

Birkinshaw, J. and Gibson, C. (2004b), "The antecedents, consequences, and mediating role of organizational ambidexterity", The Academy of Management Journal, Vol. 47 No. 2, pp. 209-226.

Brown, S.L. and Eisenhardt, K.M. (1997), "The art of continuous change: Linking complexity theory and timepaced evolution in relentlessly shifting organizations", Admin. Sci. Quart, Vol. 42 No. 1, pp. 1-3.

Cao, Q., Gedajlovic, E. and Zhang, H. (2009), "Unpacking organizational ambidexterity: Dimensions, contingencies, and synergistic effects", Organization Science, Vol. 20 No. 4, pp. 781-796.

Caspin-Wagner, K., Ellis, S. and Tishler, A. (2012), "Balancing exploration and exploitation for firm's superior performance: The role of the environment", Paper presented at the annual meetings of the Academy of Management.

Christensen, C.M. (2003), The Innovator's Dilemma, Harper Business Essentials, New York.

Conger, J.A. and Kanungo, R.N. (1987), Charismatic Leadership in Organizations, Sage, Thousand Oaks.

De Bono, E. (2009), Lateral thinking: creativity step by step, Harper and Row, New York.

Devinney, T.M. (2013), "Is microfoundational thinking critical to management thought and practice?", The Academy of Management Perspectives, Vol. 27 No. 2, pp. 81-84. https://doi.org/10.5465/amp.2013.0053

Dong, A., Garbuio, M. and Lovallo, D. (2016), “Generative sensing in design evaluation”, Design Studies, Vol. 45, pp. 68-91. https://doi.org/10.1016/j.destud.2016.01.003

Dong, A., Lovallo, D. and Mounarath, R. (2015), "The effect of abductive reasoning on concept selection decisions", Design Studies, Vol. 37, pp. 37-58.

Dorst, K. (2011), “The core of 'design thinking' and its application”, Design Studies, Vol. 32 No. 6, pp. 521532. https://doi.org/10.1016/j.destud.2011.07.006

Dresch, A., Lacerda, D.P. and Antunes, J.A.V. (2015), “'Design Science Research”, In: Dresch, A., Lacerda, D.P. and Antunes Jr, J.A.V. (Eds.), Design Science Research, Springer International Publishing, pp. 67-102.

Duncan, R. (1976), "The Ambidextrous Organization: Designing Dual Structures for Innovation", In: Kilman, R.H., Pondy, L.R. and Stevens, D. (Eds.), The Management of Organization Design, North Holland, New York, pp. 167-88.

Eisenhardt, M., Furr, N. and Bingham, C. (2010), "CROSSROADS - Microfoundations of Performance: Balancing Efficiency and Flexibility in Dynamic Environments", Organization Science, Vol. 21 No. 6, pp. 1263-1273. https://doi.org/10.1287/orsc.1100.0564

Grant, R.M. (1996), "Prospering in Dynamically-Competitive Environments: Organisational Capability as Knowledge Integration”, Organisation Science, Vol. 7 No. 4, pp. 375-387.

Hamel, G. (2002), Leading the revolution, Harvard Business School Press, Boston.

He, Z. and Wong, P. (2004), "Exploration vs. exploitation: an empirical test of the ambidexterity hypothesis", Organization Science, Vol. 15, pp. 481-494.

Junni, P. et al. (2013), "Organizational ambidexterity and performance: A meta-analysis", Academy of Management Perspectives, Vol. 27 No. 4, pp. 299-312.

Katila, R. and Ahuja, G. (2002), "Something old, something new: A longitudinal study of search behavior and new product introduction", Academy of Management Journal, Vol. 45, pp. 1183-1194.

Khazanchi, S., Lewis, M.W. and Boyer, K.K. (2007), "Innovation-supportive culture: The impact of organizational values on process innovation", Journal of operations management, Vol. 25 No. 4, pp. 871-884.

Knott, A.M. (2002), "Exploration and exploitation as complements", In: Bontis, N. and Choo, C.W. (Eds.), The strategic management of intellectual capital and organizational knowledge, Oxford University Press, New York, pp. 339-358.

Kogut, B. and Zander, U. (1992), "Knowledge of the Firm, Combinative Capabilities, and the Replication of Technology”, Organisation Science, Vol. 3 No. 3. https://doi.org/10.1287/orsc.3.3.383

Kraner, J. (2018), Innovation in High Reliability Ambidextrous Organizations: Analytical Solutions Toward Increasing Innovative Activity, Springer International Publishing: Imprint: Springer, Cham. 
Lin, H.E. et al. (2013), "Managing the Exploitation/Exploration Paradox: The Role of a Learning Capability and Innovation Ambidexterity", Journal of Product Innovation Management, Vol. 30 No. 2, pp. 262-278. https://doi.org/10.1111/j.1540-5885.2012.00998.x

Lovas, B. and Ghoshal, S. (2000), "Strategy as guided evolution”, Strategic Management Journal, Vol. 21, pp. 875-896.

Moore, G.A. (2015), Zone to Win: Organizing to Compete in an Age of Disruption, Diversion Books, New York.

Mumford, M.D. et al. (2000), "Leadership skills: Conclusions and future directions", The Leadership Quarterly, Vol. 11 No. 1, pp. 155-170.

Nicholas, J., Ledwith, A. and Bessant, J. (2015), "Selecting Early-Stage Ideas for Radical Innovation: Tools and Structures”, Research-Technology Management, Vol. 58, pp. 36-44. https://doi.org/10.5437/08956308X5804260

Nosella, A., Cantarello, S. and Filippini, R. (2012), "The intellectual structure of organizational ambidexterity: A bibliographic investigation into the state of the art", Strategic Organization, Vol. 10 No. 4, pp. 450-465.

O’Connor, G.C. (2008), "Major Innovation as a Dynamic Capability: A Systems Approach”, Journal of Product Innovation Management, Vol. 25 No. 4, pp. 313-330. https://doi.org/10.1111/j.1540-5885.2008.00304.x

O'Reilly, C. and Tushman, M. (2008), “Ambidexterity as a dynamic capability: Resolving the innovator's dilemma", Research in Organizational Behavior, Vol. 28, pp. 185-206.

O’Reilly, C. and Tushman, M. (2011), “Organizational Ambidexterity in Action: How managers explore and exploit”, California Management Review, Vol. 53 No. 5/6, pp. 5-22.

O’Reilly, C. and Tushman, M. (2013), "Organizational Ambidexterity: Past, Present, and Future”, AMP, Vol. 27, pp. 324-338. https://doi.org/10.5465/amp.2013.0025

Paap, J. and Katz, R. (2004), “Anticipating disruptive innovation”, Research-Technology Management, Vol. 47 No. 5, pp. 13-22.

Raisch, S. and Birkinshaw, J. (2008), "Organizational Ambidexterity: Antecedents, Outcomes, and Moderators", Journal of Management, Vol. 34 No. 3, pp. 375-409. https://doi.org/10.1177/0149206308316058

Raisch, S. et al. (2009), "Organizational ambidexterity: Balancing exploitation and exploration for sustained performance”, Organ. Sci., Vol. 20 No. 4, pp. 685-695.

Rothaermel, F.T. and Deeds, D.L. (2004), "Exploration and exploitation alliances in biotechnology: A system of new product development", Strategic management journal, Vol. 25 No. 3, pp. 201-221.

Salampasis, D., Mention, A.-L. and Torkkeli, M. (2015), "Trust embeddedness within an open innovation mindset", International Journal of Business and Globalisation, Vol. 14, pp. 32-57. https://doi.org/10. 1504/IJBG.2015.066099

Shapiro, L. (2000), "Multiple realizations”, Journal of Philosophy, Vol. 97 No. 12, pp. 635-654.

Sidhu, J.S., Volberda, H.W. and Commandeur, H.R. (2004), "Exploring Exploration Orientation and its Determinants: Some Empirical Evidence", Journal of Management Studies, Vol. 41, pp. 913-932. https://doi.org/10.1111/j.1467-6486.2004.00460.x

Simsek, Z. (2009), "Organizational Ambidexterity: Towards a Multilevel Understanding", Journal of Management Studies, Vol. 46 No. 4, pp. 597-624. https://doi.org/10.1111/j.1467-6486.2009.00828.x

Simsek, Z. et al. (2009), “'A typology for aligning organisational ambidexterity's conceptualizations, antecedents, and outcomes"”, Journal of Management Studies, Vol. 46 No. 5, pp. 864-894.

Smith, W.K. and Lewis, M.W. (2011), "Toward a theory of paradox: A dynamic equilibrium model of organizing", Academy of management Review, Vol. 36 No. 2, pp. 381-403.

Tighe, S. (2019), Rethinking Strategy: How to anticipate the future, slow down change, and improve decision making, John Wiley \& Sons, Richmond, Melbourne.

Turner, N., Swart, J. and Maylor, H. (2013), "Mechanisms for Managing Ambidexterity: A Review and Research Agenda", International Journal of Management Reviews, Vol. 15 No. 3, pp. 317-332. https://doi.org/10.1111/j.1468-2370.2012.00343.x

Tushman, M. and O'Reilly, C. (1996), “The ambidextrous organization: Managing evolutionary and revolutionary change", Calif. Management Rev, Vol. 38 No. 4, pp. 8-30.

Tushman, M. et al. (2010), "Organizational designs and innovation streams", Industrial and corporate change, Vol. 19 No. 5, pp. 1331-1366.

The Leadership Network (2016), Innovation The Dyson Way, The Leadership Network, available at https://theleadershipnetwork.com/article/innovation-dyson-reimagining-appliances.

Uzzi, B. (1997), "Social structure and competition in interfirm networks: The paradox of embeddedness", In: Granovetter, M. and Swedberg, R. (Eds.), The Sociology of Economic Life, Westview Press, Boulder, CO, pp. 207-238.

Vettorello, M., Eisenbart, B. and Ranscombe, C. (2019), "Toward Better Design-Related Decision Making: A Proposal of an Advanced OODA Loop", Proceedings of the Design Society: International Conference on Engineering Design. Cambridge University Press, Vol. 1 No. 1, pp. 2387-2396. https://doi.org/10.1017/dsi.2019.245 